- Additional material is published online only. To view please visit the journal online (http://dx.doi.org/10.1136/ jnnp-2013-306992)

${ }^{1}$ Department of Neurology, Janakpuri Superspeciality Hospital, New Delhi, India ${ }^{2}$ Department of Neurology, Aga Khan University, Karachi, Pakistan

${ }^{3}$ Department of Vascular Neurology, University of Virginia, Charlottesville, Virginia, USA

\section{Correspondence to} Professor Man Mohan Mehndiratta, Department of Neurology, Janakpuri Superspeciality Hospital. Janakpuri, New Delhi 110058, India;

mmehndi@hotmail.com

Received 16 January 2014 Revised 14 March 2014 Accepted 29 March 2014 Published Online First 25 April 2014

CrossMark

To cite: Mehndiratta MM, Khan M, Mehndiratta P, et al. I Neurol Neurosurg Psychiatry 2014;85: 1308-1312.

REVIEW

\title{
Stroke in Asia: geographical variations and temporal trends
}

\author{
Man Mohan Mehndiratta, ${ }^{1}$ Maria Khan, ${ }^{2}$ Prachi Mehndiratta, ${ }^{3}$ Mohammad Wasay ${ }^{2}$
}

\section{ABSTRACT}

Asian countries are in various stages of epidemiological transition and therefore exhibit a great diversity in disease patterns. Collectively, they comprise almost two-third of the world's total mortality due to stroke. The purpose of this review is to explore existing epidemiological data on stroke, highlight the temporal trends in stroke epidemiology in various regions of Asia and predict future patterns based on these observations. Our search revealed that there is a lack of good epidemiological data from most Asian countries. Whatever data exist are not comparable due to lack of standardised methodology for ascertaining stroke and its subtypes. For this and other reasons, these estimates exhibit country-to-country variation and also withincountry variability. We have also reviewed temporal trends in stroke incidence and prevalence in 12 Asian countries and the evolution of stroke subtypes over the past two decades. Important observations include a rise in stroke incidence in most Asian countries, an earlier age at onset compared with the West, a relative increase in the proportion of ischaemic strokes and a decline in haemorrhagic strokes. Among ischaemic stroke subtypes, lacunar strokes, which were once the commonest variety, are now declining. Emerging data suggest that large artery atherosclerosis and in particular that of intracranial vessels is the predominant aetiology in most Asian countries. The review also identified important gender differences in terms of stroke risk factors, prevalence and outcomes. There is need for sound epidemiological data from most countries to understand the disease better and plan policy-level interventions to decrease the burden. We identify a need for standard format or guidelines for conducting stroke epidemiological studies especially in developing Asian countries. This region must be identified as a priority region for stroke-related interventions and preventive strategies by global healthcare authorities and organisations.

\section{INTRODUCTION}

Although the age-standardised mortality due to stroke has shown a downward trend in the past two decades, the absolute numbers affected by this devastating condition are on the rise, particularly in low-to-middle income countries. ${ }^{1}$ The Asian continent harbours almost two-thirds of the world's population, and in 2002 East Asia alone comprised $60 \%$ of the world's total mortality due to stroke. ${ }^{2}$

Asia is home to a very diverse population both in terms of ethnic variability and socioeconomic differences, with countries in various stages of development and epidemiological transition. The burden of cerebrovascular disease, therefore, is also expected to exhibit geographical variability. This burden is also expected to go up further as Asian countries undergo development, their populations age and there is a change in lifestyle factors. ${ }^{3}$ South Asian countries (India, Pakistan, Bangladesh and Sri Lanka) constitute $22 \%$ of world's population and $40 \%$ of the developing world, and are the most affected regions probably accounting for more than $40 \%$ of global stroke deaths. ${ }^{4}$ Therefore, global burden of stroke and stroke-related deaths cannot be substantially reduced without interventions in Asia. Analysis of existing data is mandatory to identify current and future trends in stroke epidemiology in this part of the world.

Many regional or multinational studies (registries or cohorts) are in progress or recently completed, including stroke in young Asian women study (8 Asian countries), Asian cerebral venous thrombosis (CVT) registry (13 Asian countries) and INTERSTROKE (a global case-control study with more than 20000 cases and controls from Asia). ${ }^{56}$ These studies indicate growing collaboration and infrastructure development in developing Asian countries. Current emphasis by United Nations (UNO) and WHO on non-communicable diseases including stroke is likely to translate into more epidemiological research in this region. It is high time we analysed epidemiological data related to stroke in Asia, identified areas of research collaboration among Asian countries and set priorities for future research and advocacy in this region.

Available stroke data from Asia are largely confined by geographical boundaries of individual countries. The objective of this review is to explore the existing data on stroke from selected Asian countries, summarise the evolution of stroke epidemiology in these countries over the past 20 years and predict future patterns based on these observations. Four of these countries are from Far East Asia (China, Japan, Korea and Taiwan), three from South East Asia (Thailand, Singapore and Malaysia), three from South Asia (Pakistan, India and Bangladesh) and two from the Middle East (Iran and Israel). These 12 countries represent more than $75 \%$ of Asian population. This review looks at various themes across major parts of Asia to identify areas for future interventions.

\section{Search strategy}

For the purpose of this review, we restricted our search to 12 Asian countries, ensuring that we get adequate representation from all regions of Asia. A detailed search for all articles published since 1990 was conducted using two search engines, PubMed 
and Google Scholar. The following keywords were used along with the name of each country to identify relevant articles: "stroke", "cerebrovascular disease", "incidence of stroke", "prevalence of stroke", "stroke epidemiology", "temporal trends in stroke", "stroke subtypes", "ischemic strokes", "intracranial hemorrhage", "lacunar strokes", "large artery strokes" and "cardioembolic strokes". The search was restricted only to English language. Abstracts from the search were screened, and all articles on stroke epidemiology were selected. Both longitudinal and cross-sectional studies were included in this review.

\section{Appraisal of current epidemiological data}

Online supplementary table S1 provides a review of the most important stroke studies from these countries with details of recruitment period, methodology of stroke subtype classification, study design (hospital registries or population based) and definition of stroke and study shortcomings. ${ }^{7-18}$ It is evident that there is lack of robust epidemiological data from most Asian countries. There are wide variations in study designs, case ascertainment and stroke definitions. It is important to know how this figure for incidence or prevalence has been standardised. Use of different standard populations can change the figures substantially. This table elaborates which standard population has been used. Because of this difference, the incidence reports are not as easily comparable as these statements sound. Reader has to understand this limitation of standardisation. These variations identify a lack of standard format or guidelines for conducting stroke epidemiological studies.

\section{Incidence and prevalence}

Table 1 provides estimates of stroke prevalence and incidence from these Asian countries ${ }^{7}$ 11-24 No prevalence data are reported from Malaysia, Japan, Iran and Israel while no incidence data from Thailand, Bangladesh and Israel could be found. Data from China and India (more than 50\% of Asian population) are most robust and reliable. Reported prevalence of stroke is comparable from China and India. Very high

Table 1 Stroke prevalence and incidence in selected Asian countries

\begin{tabular}{|c|c|c|c|}
\hline Country & $\begin{array}{l}\text { Study } \\
\text { period }\end{array}$ & Prevalence & Incidence \\
\hline Japan* & $2002-2005$ & Not available & $145 / 100$ 000/year ${ }^{7}$ \\
\hline China* & 1985-1991 & $260-719 / 100000^{19}$ & $\begin{array}{l}116-219 / 100000 / \\
\text { year }^{19}\end{array}$ \\
\hline Korea* & $2004-5$ & $\begin{array}{l}1590 / 100000 \text { (age adjusted } \\
>35 \text { years) }\end{array}$ & $216 / 100000 /$ year $^{11}$ \\
\hline Taiwan* & 1986-1990 & $\begin{array}{l}1642 / 100000(\text { age } \\
>36 \text { years }^{20}\end{array}$ & $329 / 100$ 000/year ${ }^{12}$ \\
\hline Thailand* & 2010 & $1850 / 100000^{13}$ & Not available \\
\hline Malaysia* & 2010-2011 & Not available & $67 / 100000 /$ year $^{14}$ \\
\hline Singapore* & $2001-2003$ & $3650 / 100000^{21}$ & $180 / 100000 /$ year $^{21}$ \\
\hline India* & $2003-2005$ & $545 / 100000^{15}$ & $145 / 100000 /$ year $^{15}$ \\
\hline Bangladesh* & & $\begin{array}{l}300 / 100000 \text { (age } \\
>40 \text { years) }\end{array}$ & Not available \\
\hline Pakistan* & 1998 & $\begin{array}{l}4800 / 100000 \text { (age adjusted } \\
>45 \text { years) }\end{array}$ & 250/100 000/year ${ }^{24}$ \\
\hline Iran* & 2006,2010 & Not available & $\begin{array}{l}103-203 / 100000 / \\
\text { year }^{17} 18\end{array}$ \\
\hline |srael* & $\begin{array}{l}\text { Not } \\
\text { available }\end{array}$ & Not available & Not available \\
\hline
\end{tabular}

*Latest published estimates are reported here. prevalence in Pakistan and Singapore could be related to methodological issues including case ascertainment and definition. These data need confirmation by sound and reliable studies. Incidence data are comparable from China, Japan, Korea, India and Singapore ranging from 116 to 219 per 100000 per year. Reported incidence data from Pakistan are not based on a population-based study, but it is an estimate from physician's survey. These data are neither accurate nor reliable. Low incidence in Malaysia and high incidence in Taiwan and Iran (one study) need reconfirmation by sound and reliable studies.

These data set again highlight the methodological issues in conducting and reporting these studies, which could be addressed by implementation of standardised protocols and methods throughout the continent.

\section{Stroke types and subtypes}

Table 2 shows the frequencies of stroke types (ischaemic vs haemorrhage) and subtypes of ischaemic stroke (large vessel, small vessel and cardioembolic). ${ }^{25-41}$ It is obvious that the frequency of haemorrhagic stroke (labelled as intracerebral haemorrhage in many reports) is still high compared with reports from the Western countries. Haemorrhagic stroke still accounts for $20-30 \%$ cases of all strokes in these countries, except Israel, Iran and Thailand. Among ischaemic stroke, China, Taiwan and Pakistan have a high proportion of small vessel disease, while Japan, Korea and Malaysia have a higher proportion of large vessel disease. Israel, Iran and Japan also have a high frequency of cardioembolic stroke. The major issue with these data is again lack of standardisation. Only a few studies used TOAST classification. Most of the studies are hospital-based registries.

\section{Temporal trends}

It is extremely important to study temporal trends in stroke incidence and stroke types/subtypes to predict future outlook and future interventions. In this section, we will provide a brief account of changing trends in these Asian countries. A summary of these trends is provided in online supplementary table S4.

Japan: One of the best evidence about stroke epidemiology from Asia comes from Japan. In the 1950s, Japan used to have the highest mortality due to stroke, but it has since declined steeply. ${ }^{42}$ Despite this, stroke still remains the third most common cause of death in Japan. ${ }^{44}$ The Hisayama stroke registry is one of their most established cohorts. ${ }^{45}$ They report a decline in the incidence of ischemic ${ }^{46}$ as well as haemorrhagic strokes over time, ${ }^{47}$ although the decline was steeper before the 1970s and since then has been less sharp. The Miyakojima study conducted in another area of Japan reports no major changes in incidence of stroke and all its subtypes from 19881991 to 2002-2005. ${ }^{7}$ The relative proportion of ischaemic strokes has increased over time compared with haemorrhagic strokes, which has shown a steady decline. The Hisayama cohort suggests that lacunar strokes have shown a significant decrease over time, whereas the incidences of the other two subtypes have not shown much change. ${ }^{48}$

China and Hong Kong: In 2010, cerebrovascular disease was ranked as the third highest cause of mortality in urban and the first highest in rural China. ${ }^{49}$ Jiang et al ${ }^{50}$ reported temporal trends, with the incidence of intracranial haemorrhages decreasing through the 1990s and that of ischaemic strokes increasing. The Sino-MONICA Beijing ${ }^{51}$ project analysed more than 14000 strokes in Beijing from 1994 to 2004 and reports a similar trend in stroke subtypes. The burden of intracranial atherosclerosis is also substantial in China, with as many as $33-50 \%$ of patients with stroke affected by it. ${ }^{52}$ A recent study 
Table 2 Stroke subtypes as reported from various Asian studies

\begin{tabular}{|c|c|c|c|c|c|}
\hline \multirow[b]{2}{*}{ Country } & \multicolumn{2}{|c|}{ Stroke types (proportion of all strokes \%) } & \multicolumn{3}{|c|}{ Ischaemic stroke subtype (proportion of all ischaemic strokes \%) } \\
\hline & Ischaemic stroke & Haemorrhagic stroke & Large artery & Small vessel & Cardioembolic \\
\hline$J^{\prime a p a n} 2526$ & $65-74$ & $26-34$ & 54.1 & 21.0 & 22.9 \\
\hline China $^{27} 28$ & 75 & 25 & 21.5 & 40.6 & 7.5 \\
\hline Korea $^{11}$ & 76 & 24 & 36.1 & 25.4 & 17.1 \\
\hline Taiwan 2930 & 71 & 28 & 14.6 & 39.4 & 12 \\
\hline Malaysia ${ }^{33}$ & $73-80$ & $18-27$ & 59 & 28.3 & 3.4 \\
\hline Singapore 3435 & $76-80$ & $19-24$ & 41 & 35 & 10 \\
\hline India ${ }^{16} 36$ & $74-80$ & $20-32$ & 41 & 18 & 10 \\
\hline Bangladesh $^{37}$ & $61-80$ & $20-39$ & Not available & Not available & Not available \\
\hline Pakistan $^{38}$ & 79 & 21 & $26-31$ & 43 & $6-8$ \\
\hline $\operatorname{Iran}^{18} 39$ & 82 & 17 & Not available & Not available & $20-31$ \\
\hline |srael 4041 & 90 & 10 & $5-9$ & $15-28$ & $21-34$ \\
\hline
\end{tabular}

reports this aetiology in $46.6 \%$ of the 2864 stroke subjects studied and concludes that it is the most common vascular lesion in Chinese patients with cerebrovascular disease. ${ }^{53}$ There is also evidence to suggest that cardioembolic strokes have also increased in China in the past decade. ${ }^{54}$ Among Hong Kong Chinese, recent trend suggests a decrease in incidence of ischaemic strokes, whereas there is a reported increase in haemorrhagic strokes among those between 35 and 44 years of age. ${ }^{55}$

Korea: According to the Korean Stroke Society's report, ${ }^{11}$ the proportion of ischaemic strokes admissions has increased from $64.7 \%$ in 2000 to $76.1 \%$ in 2009 . The proportion of haemorrhagic strokes has gone down steadily. According to these data, large artery atherosclerosis was and still remains the predominant aetiology found in $36.1 \%$ of patients with ischaemic stroke. Small vessel disease has shown a downward trend, whereas cardioembolism increased during this time. The study also reports a predominant intracranial atherosclerosis, although extracranial disease tended to show a rising trend over the study period. Slightly older data from 1999 to 2007 also show an increase in intracranial disease burden over time. ${ }^{56}$

Taiwan: A recently published study has shown a temporal rise in the burden associated with ischaemic strokes in Taiwan from 2000 to $2005 .^{57}$ Recent data suggest that the incidence of haemorrhagic strokes is higher in Taiwan compared with the white and black populations of North America and Europe but lower than the incidence reported from China and Japan. ${ }^{33}$ Compared with data from 1995, lacunar stroke proportion has gone up from $29 \%$ and that of cardioembolism has come down. ${ }^{58}$

Thailand: Stroke is among the top three leading causes of mortality in Thailand. ${ }^{59}$ In 1998, a study conducted on elderly Thai population revealed a prevalence of $1.12 \% .{ }^{60}$ The frequency of haemorrhagic stroke decreased from 22\% (in 2003) to 13\% (in 2012). ${ }^{6131}$ Among ischaemic stroke subtypes, recent data suggest a very high percentage of intracranial atherosclerosis $52.6 \%$ of all ischaemic strokes) as the predominant aetiology. ${ }^{32}$

Malaysia: According to the most recent estimates, stroke is the fifth leading cause of death in Malaysia. ${ }^{14}$ The National Stroke Registry reports ischaemic strokes as the predominant variety found in $73.3 \%$ of all patients with stroke. ${ }^{33}$ This proportion has not changed since the late 1990 s when a hospital-based study reported ischaemic strokes in $72 \%{ }^{62}$ The proportion of small vessel disease is reported as declining trend from $62 \%$ (2003) to $28 \%(2012) .^{33}$

Singapore: Stroke is the fourth leading cause of death in Singapore. ${ }^{21}$ When temporal trend was analysed between 2000 and 2005 , no significant changes were seen in the relative proportions of the stroke subtypes.

India: Data from India report consistent trends in stroke incidence and types/subtypes. The variations in frequencies of haemorrhagic stroke and small vessel diseases are largely attributed to geographical variations.

Bangladesh: Stroke is the third leading cause of death in Bangladesh. ${ }^{37}$ No data are available on ischaemic stroke subtypes so far. No data are reported addressing temporal trends related to stroke from Bangladesh.

Pakistan: Recently, a multicentre stroke registry was analysed by our stroke group, ${ }^{63}$ and large artery atherosclerosis seems to have taken over as the predominant subtype found in $35.7 \%$ subjects followed by small vessel disease. Cardioembolic strokes have also gone up in proportion to $11.8 \%$ from 6 to $8 \%$ previously reported. Wasay et $a l^{64}$ evaluated the temporal trends for intracerebral haemorrhage from 1988 to 2005 using hospitalbased data. They concluded that the number of hospital admissions went up significantly over time, proportion of female victims increased and age at onset decreased by about 5 years.

Iran: In 2001, the Khorasan Stroke Registry was established with the view to study stroke incidence and patterns in Southern Khorasan. This study reported a rise in incidence of stroke from 84.16 to $103.23 / 100000$ population per year from 2001 to 2005 . No substantial temporal changes in stroke types/ subtypes are reported. ${ }^{65}$

Israel: The National Acute Stroke Israeli (NASIS) registry has recently published their results on 6279 patients with stroke from 28 hospitals across the country. ${ }^{40}$ There has not been much change in stroke type/subtype proportions from 2004 to 2010. The authors also report a significant decline in the proportion of small vessel strokes in elderly subjects ( $>85$ years of age) from 2004 to 2010 .

Having reviewed the stroke data from individual countries, the following observations can be made. There is lack of robust epidemiological data from most Asian countries. There is an increase in absolute number of stroke cases, although the incidence of stroke has come down in countries such as Japan. Ischaemic strokes are the predominant subtype in all countries and increasing in relative proportion. Haemorrhagic strokes have in the past accounted for more than a third of all strokes in Asian countries, particularly in East and South Asia. However, they have decreased in proportion over time. Large artery atherosclerosis is the predominant aetiology in most East Asian, South East Asian and South Asian countries. 
Atherosclerosis is, in most cases, affecting the intracranial vasculature and is suggested to be the most common cause of stroke in Asians. ${ }^{66}$ There are some data to suggest the high and rising burden of cardioembolic strokes, particularly from China and the Middle East. ${ }^{67}$

\section{Gender differences}

Differences exist between men and women in terms of risk factors and stroke prevalence in Asian countries. A recent study from Korea found more atrial fibrillation in Korean women with stroke compared with men in all ages, and more diabetes in women greater than 65 years of age. ${ }^{68}$ The risk factors in younger women particularly during pregnancy and puerperium are different. This region probably represents highest prevalence area of pregnancy and postpartum stroke. ${ }^{69}$ A prior study by our group demonstrated that among pregnancy-related strokes in women from five Asian countries, cortical venous thrombosis accounted for almost half of all cases. ${ }^{69}$ Gender differences exist in terms of stroke outcomes also. A recent study from China ${ }^{70}$ demonstrates many gender differences, the most significant of which was a higher dependency level at 1 year postischaemic stroke among women compared with men. Stroke in women is poorly reported in South Asia. Stroke is the leading cause of death in women above age 60 years in South Asia. ${ }^{71}$

\section{Mean age at stroke onset and young stroke}

The mean age of stroke in some Asian countries (Pakistan 59 years; China 60 years; India 63 years) is less compared with the Western countries (USA 68 years; Italy 71 years). ${ }^{4}$ There are data to suggest that the onset of stroke and ischaemic heart disease is almost 10 years earlier in this region. ${ }^{4}$ A populationbased study carried out in Masshad (Iran) in $2006^{18}$ reported that ischaemic strokes were occurring one decade earlier than in the Western countries. Some of the Indian studies have shown that about $10-15 \%$ of strokes occur in population below the age of 40 years. ${ }^{72}$ Prasad $e t a l^{73}$ have reviewed data from Indian studies on young stroke, and they conclude that although traditional risk factors are also quite abundant in this age group, cardioembolic, venous and cryptogenic stroke make up a substantial proportion of all strokes. Wasay et $a l^{5}$ describe strokes in young women from eight Asian countries and report cortical venous thrombosis as the predominant cause of stroke in this group. Large artery atherosclerosis and cardioembolism were the other important causes identified in this study. From Taiwan, Lee $e t a l^{74}$ found other determined and undetermined aetiologies to make up a significant proportion of stroke in the young with small vessel and cardioembolism being other important causes. Ghandehari reports cardioembolism as the proximate aetiology in $54 \%$ of young Iranian patients with stroke. $^{75}$

\section{CONCLUSION}

Pattern of stroke in Asia shows geographical diversity and is evolving with time. The absolute burden of the condition is rising, and measures need to be taken to address risk factors for atherosclerosis, which is the predominant mechanism of stroke in this region. There is need for sound epidemiological data from most countries to understand the disease better and plan policy-level interventions to decrease the burden. We identify a need for standard format or guidelines for conducting stroke epidemiological studies especially in developing Asian countries. Future research should focus on better epidemiological studies to gauge the true burden of the condition. Comparative studies between various Asian regions may help elucidate mechanisms of stroke that are specific to race and ethnicity. Global burden of stroke and stroke-related deaths cannot be substantially reduced without interventions in Asia, especially in South Asia and China. This region must be identified as a priority region for stroke-related interventions and preventive strategies by the WHO, World Stroke Organization (WSO) and other global healthcare authorities and organisations. We propose that the WSO or Asia-Pacific Stroke Organization should develop and publish these guidelines. Standardisation of future stroke epidemiological research across Asian countries should become a priority area for stroke researchers and organisations in Asia. This will definitely lead to a better understanding of stroke epidemiology in this region.

Acknowledgement We thank Dr Natasha Singh Gulati for her valuable inputs and proofreading of the manuscript.

Contributors MMM conceived and designed the manuscript, data acquisition and critical review of the manuscript. MK drafted and reviewed the manuscript. PM and MW reviewed the manuscript.

Competing interests None.

Patient consent Obtained.

Provenance and peer review Commissioned; externally peer reviewed.

\section{REFERENCES}

1 Feigin VL, Forouzanfar MH, Krishnamurthi R, et al. Global and regional burden of stroke during 1990-2010: findings from the Global Burden of Disease Study 2010. Lancet 2014;383:245-55.

2 World Health Organization (WHO). Global Status Report on Alcohol. Geneva: World Health Organization, 2004. http://www.who.int/substance_abuse/publications/ global_status_report_2004_overview.pdf (accessed 14 Mar 2014).

3 Burke TA, Venketasubramanian RN. The epidemiology of stroke in the East Asian region: a literature-based review. Int J Stroke 2006;1:208-15.

4 Wasay M, Khatri IA, Kaul S. Stroke in South Asian countries. Nat Rev Neurol 2014;10:135-43

5 Wasay M, Kaul S, Menon B, et al. Ischemic stroke in young Asian women: risk factors, subtypes and outcome. Cerebrovasc Dis 2010;30:418-22.

6 Wasay M, Kamal A, Khealani B, et al. Asian cerebral venous thrombosis registry: study protocol. J Vasc Interv Neurol 2009;2:169-71.

7 Sugama C, Isa K, Okumura K, et al. Trends in the incidence of stroke and cardiovascular risk factors on the isolated island of Okinawa: the Miyakojima study. J Stroke Cerebrovasc Dis 2013:22:e118-23.

8 Hata J, Ninomiya T, Hirakawa Y, et al. Secular trends in cardiovascular disease and its risk factors in Japanese: half-century data from the Hisayama Study (1961-2009). Circulation 2013;128:1198-205.

9 Zhao D, Liu J, Wang W, et al. Epidemiological transition of stroke in China: twenty-one-year observational study from the Sino-MONICA-Beijing Project. Stroke 2008;39:1668-74.

10 Sun $X G$, Wang $Y L$, Zhang $N$, et al. Incidence and trends of stroke and its subtypes in Changsha, China from 2005 to 2011. J Clin Neurosci 2014;21:436-40.

11 Hong KS, Bang OY, Kang DW, et al. Stroke statistics in Korea: part I. Epidemiology and risk factors: a report from the Korean stroke society and clinical research center for stroke. J Stroke 2013;15:2-20.

$12 \mathrm{Hu} \mathrm{HH}$, Sheng WY, Chu FL, et al. Incidence of stroke in Taiwan. Stroke 1992:23:1237-41.

13 Hanchaiphiboolkul S, Poungvarin N, Nidhinandana S, et al. Prevalence of stroke and stroke risk factors in Thailand: Thai Epidemiologic Stroke (TES) Study. J Med Assoc Thai 2011;94:427-36.

14 Neelamegam M, Looi I, Cheah WK, et al. Stroke incidence in the South West District of the Penang Island, Malaysia: PEARLs: Penang Acute stroke research longitudinal study. Prev Med 2013;57(Suppl):S77-9.

15 Das SK, Banerjee TK, Biswas A, et al. A prospective community-based study of stroke in Kolkata, India. Stroke 2007;38:906-10.

16 Sridharan SE, Unnikrishnan JP, Sukumaran S, et al. Incidence, types, risk factors, and outcome of stroke in a developing country the trivandrum stroke registry. Stroke 2009:40:1212-18.

17 Oveisgharan S, Sarrafzadegan N, Shirani S, et al. Stroke in Isfahan, Iran: hospital admission and 28-day case fatality rate. Cerebrovasc Dis 2007;24:495-9.

18 Azarpazhooh MR, Etemadi MM, Donnan GA, et al. Excessive Incidence of Stroke in Iran Evidence From the Mashhad Stroke Incidence Study (MSIS), a Population-Based Study of Stroke in the Middle East. Stroke 2010;41:e3-e10. 
19 Liu M, Wu B, Wang WZ, et al. Stroke in China: epidemiology, prevention, and management strategies. Lancet Neurol 2007;6:456-64.

$20 \mathrm{Hu} \mathrm{HH}$, Chu FL, Chiang BN, et al. Prevalence of stroke in Taiwan. Stroke 1989;20:858-63.

21 Venketasubramanian N, Chen CL. Burden of stoke in Singapore. Int J Stoke 2008;3:51-4.

22 Mohammad QD, Habib M, Hoque A, et al. Prevalence of stroke above forty years. Mymensingh Med J 2011;20:640-4.

23 Jafar TH. Blood pressure, diabetes, and increased dietary salt associated with stroke-results from a community-based study in Pakistan. J Hum Hypertens 2006;20:83-5.

24 Khatri IA, Wasay M. Can we stop the stroke epidemic in Pakistan? J Coll Physicians Surg Pak 2011;21:195-6.

25 Shigematsu K, Nakano H, Watanabe $Y$, et al. Characteristics, risk factors and mortality of stroke patients in Kyoto, Japan. BMJ Open 2013;3:e002181.

26 Turin TC, Kita Y, Rumana N, et al. Ischemic stroke subtypes in a Japanese population Takashima Stroke Registry, 1988-2004. Stroke 2010;41:1871-6.

27 Wei JW, Arima H, Huang Y, et al. Variation in the frequency of intracerebral haemorrhage and ischaemic stroke in China: a national, multicentre, hospita register study. Cerebrovasc Dis 2010;29:321-27.

28 Hao Z, Liu M, Wang D, et al. Etiologic subtype predicts outcome in mild stroke: prospective data from a hospital stroke registry. BMC Neurol 2013;13:154

29 Jeng JS, Lee TK, Chang YC, et al. Subtypes and case-fatality rates of stroke: A hospital-based stroke registry in Taiwan (SCAN-IV). J Neurol Sci 1998;156:220-26.

30 Wu CY, Wu HM, Lee JD, et al. Stroke risk factors and subtypes in different age groups: A hospital-based study. Neurol India 2010;58:863-8.

31 Chinwatanakul S, Boonyapisit K, Pornsriniyom D, et al. Siriraj Acute Stroke Unit: 10 years experience. J Med Assoc Thai 2012;95(Suppl 2):S235-44.

32 Ratanakorn D, Keandoungchun J, Tegeler $\mathrm{CH}$. Coexistent extra-and intracranial stenosis, cervical atherosclerosis, and abnormal ankle brachial index in acute ischemic stroke. J Stroke Cerebrovasc Dis 2012;21:782-9.

33 Nazifah SN, Azmi IK, Hamidon BB, et al. National Stroke Registry (NSR): Terengganu and Seberang Jaya experience. Med J Malaysia 2012;67:302-4.

34 Sun $\mathrm{Y}$, Lee $\mathrm{SH}$, Heng $\mathrm{BH}$, et al. 5-year survival and rehospitalization due to stroke recurrence among patients with hemorrhagic or ischemic strokes in Singapore. BMC Neurol 2013:13:133.

35 De Silva DA, Woon F-P, Lee M-P, et al. South Asian patients with ischemic stroke intracranial large arteries are the predominant site of disease. Stroke 2007;38:2592-4.

36 Kaul S, Sunitha P, Suvarna A, et al. Subtypes of Ischemic Stroke in a Metropolitan City of South India (One year data from a hospital based stroke registry). Neurol India 2002;50(Suppl):S8-S14.

37 Islam MN, Moniruzzaman M, Khalil Ml, et al. Burden of stroke in Bangladesh. Int Stroke 2013:8:211-13.

38 Syed NA, Khealani BA, Ali S, et al. Ischemic stroke subtypes in Pakistan: the Aga Khan University Stroke Data Bank. J Pak Med Assoc 2003:53:584-8.

39 Ghandehari K, Izadi Mood Z. Cardiac sources of embolism in Iranian stroke patients. ARYA Atheroscler 2010;2. http://arya.mui.ac.ir/index.php/arya/article/view/ 128 (accessed 14 Mar 2014)

40 Tanne D, Koton S, Molshazki N, et al. Trends in Management and Outcome of Hospitalized Patients With Acute Stroke and Transient Ischemic Attack The National Acute Stroke Israeli (NASIS) Registry. Stroke 2012;43:2136-41.

41 Gur AY, Tanne D, Bornstein NM, et al. Stroke in the Very Elderly: Characteristics and Outcome in Patients aged $\geq 85$ years with a first-ever Ischemic Stroke. Neuroepidemiology 2012;39:57-62.

42 Liu L, Ikeda K, Yamori Y. Changes in Stroke Mortality Rates for 1950 to 1997 A Great Slowdown of Decline Trend in Japan. Stroke 2001;32:1745-9.

43 Mirzaei M, Truswell AS, Arnett K, et al. Cerebrovascular disease in 48 countries: secular trends in mortality 1950-2005. J Neurol Neurosurg Psychiatry 2012;83:138-45

44 Hachinski V. Stroke in Japanese. Stroke 2006;37:1143.

45 Kubo M, Kiyohara Y, Kato I, et al. Trends in the incidence, mortality, and survival rate of cardiovascular disease in a Japanese community The Hisayama Study. Stroke 2003:34:2349-54.

46 Kubo M, Hata J, Doi Y, et al. Secular trends in the incidence of and risk factors for ischemic stroke and its subtypes in Japanese population. Circulation 2008;118:2672-8.

47 Gotoh S, Hata J, Ninomiya T, et al. Trends in the Incidence and Survival of Intracerebra Hemorrhage by its Location in a Japanese Community. Circ J 2014;78:403-9.
48 Kubo M, Kiyohara Y, Ninomiya T, et al. Decreasing incidence of lacunar vs other types of cerebral infarction in a Japanese population. Neurology 2006:66:1539-44.

49 Li Y, Liu H, Wang J, et al. Variable Lengths of Stay among Ischemic Stroke Subtypes in Chinese General Teaching Hospitals. PloS ONE 2012;7:e45101.

50 Jiang $B$, Wang $W Z$, Chen $\mathrm{HL}$, et al. Incidence and trends of stroke and its subtypes in China results from three large cities. Stroke 2006;37:63-8.

51 Zhao D, Liu J, Wang W, et al. Epidemiological transition of stroke in China twenty-one-year observational study from the Sino-MONICA-Beijing project. Stroke 2008:39:1668-74.

52 Wong LK. Global burden of intracranial atherosclerosis. Int J Stroke 2006;1 $158-9$

53 Wang Y, Liu L, Wong Y, et al. International Stroke conference meeting abstract. A multicenter study of the prevalence and outcomes of intracranial large artery atherosclerosis among stroke and TIA patients in China. Stroke 2012;43:A120-A http://stroke.ahajournals.org/cgi/content/meeting_abstract/43/2_MeetingAbstracts/ A120\#otherarticles (accessed 14 Mar 2014).

54 Soo $Y$, Huang $X$, Chen $X Y$, et al. Prevalence of cardioembolic stroke increased significantly in Chinese population in the past 10 years. J Neurol Sci 2013;333: e161.

55 Chau PH1, Woo J, Goggins WB, et al. Trends in stroke incidence in Hong Kong differ by stroke subtype. Cerebrovasc Dis 2011;31:138-46.

56 Kim YD, Choi HY, Cho HJ, et al. Increasing frequency and burden of cerebral artery atherosclerosis in Korean stroke patients. Yonsei Med J 2010;51:318-25.

57 Chen CY, Huang YB, Tzu-Chi Lee C. Epidemiology and disease burden of ischemic stroke in Taiwan. Int J Neurosci 2013;123:724-31.

58 Chan CL, Ting HW, Huang HT. The incidence, hospital expenditure, and, 30 day and 1 year mortality rates of spontaneous intracerebral hemorrhage in Taiwan. J Clin Neurosci 2014:21:91-4.

59 Poungvarin N. Burden of stroke in Thailand. Int J Stroke 2007;2:127-28.

60 Viriyavejakul A, Prayoonwiwat N, Chaisevikul R, et al. Epidemiology of stroke in the elderly in Thailand. Chot Mai Het Thang Phaet 1998;81:497-505.

61 Piravej K, Wiwatkul W. Risk factors for stroke in Thai patients. J Med Assoc Thai 2003;86(Suppl 2):S291-8.

62 Ong TZ, Raymond AA. Risk factors for stroke and predictors of one-month mortality. Singapore Med J 2002;43:517-21.

63 Khealani BA, Khan M, Tariq M, et al. Ischemic strokes in Pakistan: Observations from the National Acute Ischemic Stroke Database. J Stroke Cerebrovasc Dis Published online April 5, 2014. doi:http://dx.doi.org/10.1016/j. istrokecerebrovasdis.2014.01.009

64 Wasay M, Khatri IA, Khealani B, et al. Temporal trends in risk factors and outcome of intracerebral hemorrhage over 18 years at a tertiary care hospital in Karachi, Pakistan. J Stroke Cerebrovasc Dis 2012;21:289-92.

65 Ghandehari K, Izadi Z. The Khorasan Stroke Registry: results of a five-year hospital-based study. Cerebrovasc Dis 2006;23:132-9.

66 Khan M, Naqvi I, Bansari A, et al. Intracranial atherosclerotic disease. Stroke Res Treat 2011;2011:282845.

67 Tse HF, Wang YJ, Ahmed Ai-Abdullah M, et al. Stroke prevention in atrial fibrillation —an Asian stroke perspective. Heart Rhythm 2013:10:1082-8.

68 Park TH, Ko Y, Lee SJ, et al. Gender differences in the age-stratified prevalence of risk factors in Korean ischemic stroke patients: a nationwide stroke registry-based cross-sectional study. Int I Stroke 2013

69 Khan M, Wasay M, Menon B, et al. Pregnancy and puerperium-related strokes in asian women. J Stroke Cerebrovasc Dis 2013;22:1393-8.

70 Wang Z, Li J, Wang C, et al. Gender differences in 1-year clinical characteristics and outcomes after stroke: results from the China National Stroke Registry. PLOS ONE 2013:8:e56459.

71 Vibha, Laskar AR. Women's health: beyond reproductive years. Indian J Public Health 2011;55:247-51.

72 Srinivasan K. Ischemic cerebrovascular disease in the young. Two common causes in India. Stroke 1984;15:733-35.

73 Prasad K, Singhal KK. Stroke in young: an Indian perspective. Neurol India 2010;58:343-50.

74 Lee TH, Hsu WC, Chen CJ, et al. Etiologic study of young ischemic stroke in Taiwan. Stroke 2002; 55:247-51.

75 Ghandehari K, Moud ZI. Incidence and etiology of ischemic stroke in Persian young adults. Acta Neurol Scand 2006;113:121-4. 